\title{
Gatekeepers of a complex field?
}

DEBORAH OSBERG, Editor-in-chief

University of Exeter (UK)

WILLIAM E. DOLL JR., Associate Editor

Louisiana State University (US) and University of Victoria (Canada)

DONNA TRUEIT, Associate Editor

University of Victoria (Canada)

It is our pleasure to take over the editorship of this online journal from founding coeditors Brent Davis and Renata Phelps. In the last four years Brent and Renata have worked to establish a solid foundation for this forum and have attracted a most interesting range of contributions. As we see it, our task as their successors is to ensure that the journal grows in strength and reputation as well as providing an increasingly useful space of conversation for those interested in the idea of complexity in relation to education and educational research. The challenge, however, is to do so in a way that is not at odds with the notion of complexity itself.

For us, editing a journal of complexity and education raises an interesting philosophical problem associated with the notion of gatekeeping1. We believe that in deciding which information will go forward and which will not, the traditional gatekeeping role of journal editors (and the reviewers they work with) can be

\footnotetext{
${ }^{1}$ This discussion is based on an AERA presentation given by D. Osberg in March 2008 entitled Gatekeeping in the Network Age (presented as part of a symposium on "Academic Publishing in the Digital Age," in Division D (Research and Measurement).
} 
understood as policing. Gatekeeper-police impose (and enforce) an already existing "official" order on the system (or academic field) - i.e., an external order - which ensures that "renegade" or "sub-standard" outsiders are prevented from entering. This policing activity, however, can be considered fundamentally anti-complexity if we understand complexity in terms of self-organization and the spontaneous emergence of new dynamic forms of order from within (rather than outside of) the complex system itself. In short, the idea of externally imposed order (policing) is anathema to complexity thinking. Policing reduces complexity and inhibits emergence. It is also antithetical to research, the purpose of which is to go beyond the already known to open new spaces of thought (or forms of order) which cannot be judged in terms of the standards of the known (see Osberg and Biesta, 2007).

In a session on academic publishing at AERA earlier this year, Noel Gough revisited an interesting tale about Benoit Mandelbrot, the founder of fractal geometry, which he first related in 1991 and which, to our minds, perfectly illustrates the problem with gatekeeping-as-policing. According to this account (Gough, 1991) it was only after finding an article on measuring coastlines in a Yorktown (US) library's rubbish that Mandelbrot began accessing articles relegated to obscure journals ("the trash cans of science") which again and again described the world as complicated, erratic, bizarre and unclassifiable. It was from such "renegade" or "sub-standard" literature that Mandelbrot was able to develop his ground-breaking ideas about the mathematical representation of chaos. ${ }^{2}$ For Noel this anecdote contains salutary lessons for those who hold "gatekeeper" roles.

We live with the possibility that what we reject-and which may thus remain unpublished or be relegated to 'obscure journals' - could be highly significant within frames of reference different from those we use as criteria for an article's acceptability for publication (Gough, 1991).

It is clear that there is much "out there" that never gets published which could be useful. But journal editors cannot publish everything submitted. For example some articles submitted to Complicity appear to have no connection whatsoever to complexity or even to education and this implies some form of selection must always take place. Without such a selection the journal would lose its special focus and purpose as a journal of complexity and education. Nevertheless, the question remains as to just how much (or how little) policing is necessary or desirable to maintain the standing of the journal. Rather than attempt to answer this question directly, we have found it more productive to focus instead on understanding gatekeeping in complex or "emergentist" terms. To understand how such gatekeeping might take form, it is necessary to take a short digression into theory.

Let us begin with the notion of "academic standards" and the problem of relativism. Important as academic standards may be in defining the strength, reputation and usefulness of a journal to its community of readers, it is equally important to realize that

\footnotetext{
${ }^{2}$ As Noel comments in his paper, the fractals known as the 'Mandelbrot set' are among the most enduring popular icons of chaos theory.
} 
choices about what information to discard and what to let pass are not simple choices guided by some standard set of questions about the "quality" and "suitability" of a piece of research. Judgments about "quality" and "suitability" are based on a complex web of influences, preferences, motives and common values. Such judgments, in other words, are socially situated. They are agreed upon social conventions and norms rather than universal norms. This creates at least two problems for journal editors.

First, from a relativist point of view, gatekeepers are understood not to be policing standards per se, but as being responsible for perpetuating particular standards which they deem "acceptable" for the research field as they define it. Such standards can no longer be touted as objective standards of quality and hence the decisions of gatekeeper "experts" can no longer be considered to be more legitimate than those of non-experts. Because there is no "one-size-fits-all" solution, the application of particular standards is always biased in favor of certain points of view while excluding others. In short, the relativist view suggests that the closely related ideas of "academic standards" and "gatekeeping" are highly questionable constructs, of which journal editors should remain wary.

Second, if judgments about standards of quality are products of agreed upon social conventions then it becomes entirely legitimate for those who are no longer satisfied with the quality criteria of a certain set of social conventions to break away and form a new group with new standards. The establishment of multiple "breakaway" groups, each operating according to their own standards, leads to a situation in which there will always be a context in which a particular research article must be judged by (certain) gatekeepers to be of a high enough standard for publication. The problem, of course, is that if it is possible to form new groups with new criteria of legitimacy and quality whenever certain standards no longer suit us $^{3}$ then we have to concede that every point of view, every piece of research, taken in context, is as legitimate as every other. In short the relativist view strips critical judgment of its meaning and we are left with what is often termed "anything goes" relativism4 (see, e.g., Adelman, 1996). Journal editors appear, therefore, to be faced with a choice between two evils. Either they must be academically and politically insensitive (some would say despotic) by imposing their own biased standards of quality on submissions or they must give up the attempt to police standards and in this way open the doors of academia to "anything goes" relativism. The way out of this impasse, so we believe, lies in an emergentist (or "complexivist") understanding of gatekeeping.

Understanding gatekeeping in emergentist terms requires that we focus on the (lack of) boundaries of the academic field in question. To put this another way, we may understand the standards and limits of any particular academic field either as well

\footnotetext{
${ }^{3}$ With the World Wide Web it is now also possible for researchers to publish their work in the absence of gatekeepers (for example in the form of personal websites, blogs and the like) and with the development of advanced search tools such a Google these articles as easily accessible as those published in "reputable" journals (and sometimes even more so!).

${ }^{4}$ This being a situation in which there is no longer any distinction between "rigorous academic knowledge" and mere "noise."
} 
defined and closed or as fluid and open. When the boundaries and standards of a particular academic field are understood to be well defined this leads us to believe that it must be the responsibility of the gatekeepers of that field - who are themselves products of the field they are gatekeeping - to protect the field from "outside," non-conformist and "sub-standard" contributions. It is the gatekeepers responsibility to protect the integrity of the field. However, it is seldom the case that the boundaries of a field are always neatly defined. Richard Edwards suggests that the "bounded field" metaphor in some instances (in this context he used the example of lifelong learning) may be "displaced by a de-differentiated and more diverse moorland" which "signifies a rich metaphorical space of exploration, about and upon which some discourses are stronger than others, with effects of re-differentiation" (Edwards, 1997, p. 67) ${ }^{5}$. In the "complexity and education" research field (as in many other fields in the social as well as the "hard" sciences) contributions can be inter-, cross-, or transdisciplinary as Brent and Renata discussed in a previous editorial for this journal (Davis \& Phelps, 2005).

The point is, when the boundaries of a field are not clear cut - when indeed the "field" is a dangerous "moorland" with overlapping and crisscrossing standards many of which are not formerly and formally recognized by the field's contributing discourses, it is impossible to undertake anything but the most superficial of policing activities for there are no longer any clear cut standards by which to judge the quality of a contribution or make exclusions. When the boundaries of a "field" of knowledge are open, it becomes clear that gatekeepers cannot know what is required to police the field because pre-given and official standards do not exist. Indeed it makes no sense to even think in such terms. Since we cannot police boundaries that do not exist we must understand the gatekeeping role as something altogether different from policing. Getting away from the policing issue (how much or how little to police the boundaries of a field) means the relativist dilemma disappears. It is no longer necessary for gatekeepers to make an impossible choice between either policing academic standards (and being academically and politically insensitive or despotic) or not policing academic standards (and opening the door to "anything goes" relativism). The question of which bad solution to choose is, quite simply, no longer a relevant question and this is what gets us beyond the relativist dilemma.

But how do we understand gatekeeping in emergentist terms? For this we believe it is also necessary to understand knowledge in emergentist terms (see Osberg and Biesta, 2007). If we think with the open relational logic of complexity it becomes possible to understand all knowledge as already interconnected in complex and non-linear relationships. Knowledge, in other words, cannot exist in the absence of interconnectivity. It does not exist in a vacuum but appears only in relational interactions. Wherever interchange takes place - wherever there is an interplay of ideas - knowledge appears or "emerges." Moreover, the nature of the knowledge that appears cannot be predicted from even the most exhaustive analysis of the interacting elements that facilitated its appearance. When new knowledge appears, in other words, it is radically

\footnotetext{
${ }^{5}$ See also Edwards (2006).
} 
new. It is invented not calculated. It therefore cannot be assessed in terms of prior standards. If these are the conditions under which new knowledge comes into being, then the free (unpoliced) exchange of ideas is the primary tool by means of which such knowledge comes into being. It is in facilitating the exchange of ideas, the interplay of ideas, not the policing of ideas that enables a field to "come into presence" (Biesta, 2006).

But giving up the idea of policing the boundaries of a field does not mean dropping all values. It means, rather, putting into play the many different values that present themselves. This puts gatekeepers in an interesting position in relation to knowledge. Whereas from a closed system perspective (where the boundaries of the field are understood to be clear cut) gatekeepers are the knowledge-police, protecting it from harmful or weakening forces by keeping "unauthorized" forces out, they are, from an emergentist or open systems perspective the ones who shepherd or invite in the "unauthorized" forces, allowing them to take up an existence alongside more traditional contributions. Such invitations provide a space for conversation, a space in which a "field" can continuously re-invent itself. Gatekeeping in this regard is no longer an activity of policing, but an activity of facilitating engagement between different forms of knowledge, different meanings, so that something else can take place. What takes place cannot be described before it appears as we cannot know where the search for connected meaning will take us.

To be loyal to the idea of complexity we believe gatekeepers of unbounded "fields" of knowledge - such as the field of complexity and education - need to maintain a humble attitude towards their field. They do not rule the field (as its "experts" arrogantly policing its borders and managing its growth) but work to ensure that a space remains open for new forms of knowledge, that is, knowledge different from and perhaps challenging to their own ideas and standards of quality, to emerge though conversation. In this sense gatekeepers hold the gate open. ${ }^{6}$

In line with this sentiment, we open our first issue of Complicity with a broad range of articles that address the idea (rather than The Theory) of complexity in one way or another. In addition to the regular featured articles and the Semantic Play section we have included short responses to - or reflections upon - some of the featured articles in an attempt to open discussion on various understandings of complexity and its role in education. In this issue all responses to the feature articles were invited, but in future issues we would be delighted to accept submissions. As well, we have included a new section - "Vignettes" which will display short descriptions of evocative episodes via either prose, poetry, photograph, or drawing. Here authors are free to address the idea of complexity in its relation to education in a more "artistic" (rather than traditionally "academic") style. We anticipate that these pieces will have broad appeal to many of our readers who are not specifically concerned with educational research, but are looking for insights into their teaching practice and we also welcome future submissions to this new

\footnotetext{
${ }^{6}$ During a discussion at AERA 2008 (see footnote 1), Barney Ricca inspired the idea of gatekeepers as gateopeners rather than police by reminding us that a person at a gate is not necessarily one who makes entry difficult. Gatekeepers can also facilitate entry.
} 
section. In future issues we would also like to include a "letters" section, so please write in if there are relevant academic issues you feel should be aired.

In this issue the first feature article by Eileen Johnson uses key elements of Bronfenbrenner's ecological-contextual theory and complexity to put forward an alternative to simplistic linear models of accountability in education which fail to consider the complexity of interactions that result in student achievement. Following this, is an article by Jérôme Proulx, who explores ways in which Maturana and Varela's theory of cognition can be differentiated from constructivist theories. Proulx's ideas are reflected upon in a piece by Bill Doll who opens the conversation by elaborating these ideas in relation to the (non)constructivism of John Dewey. In the third feature article Wendy Nielsen, Cynthia Nicol and Jenipher Owuor draw on complexity to develop a "culturally responsive mathematics pedagogy" which aims to open new possibility for curriculum development, Aboriginal schooling and cultural renewal, while ensuring success for Aboriginal students. We are most fortunate to have elicited a response to this paper by Coyote and Raven (Aka Peter Cole \& Pat O’Riley). Our final feature article, authored by Inna Semetsky, looks to Tarot as a mode of teaching, arguing that Tarot is well suited to capturing the complexity of aspects of the educational project of "knowing thyself.... and others." Tony Whitson responds to this rather controversial article pointing out how, in dealing with the topic of Tarot, Semetsky has skilfully woven together a wide array of theoretical discourses and in so doing opened vast possibilities for "complicated [or perhaps complex!] conversation."

In the Semantic Play section of this issue, and extending the theme of intellectual diversity and openness to different perspectives, we present four invited contributions. The first is a contribution from Heesoon Bai who addresses the issue of ethics in education from a complex Zen perspective. Next we have a piece by Bernard Ricca, who discusses the notion of enframing, followed by Walter Gershon who takes on validity. Finally, Sarah Smitherman Pratt plays with the notion of bifurcations.

Following on from the semantic Play section is our new Vignettes section which includes three evocative descriptions of complexity operating in educational settings. The first is a piece by the Women Writing Women (WWW) Collective who show how gatherings of the WWW collective offer an emergent space for deeply personal, yet public explorations into meaning-making. In the second vignette, Perrin Blackman shows how the language of "new science" can help ESL teachers describe and discover ways to allow for necessary classroom flexibility while also respecting conventional curriculum standards and outcomes. This is followed by Katherine Low's piece, Holy Ground which explains how, in the complex richness of recursion and feedback loops, teaching and learning holds implications beyond the classroom. This leads her to conceptualizes the classroom as a holy place.

The issue ends with four book reviews, collected and edited by our new book review editor, Darren Stanley.

Once again we wish to express our delight at taking over the helm of Complicity and hope you enjoy the journey! 


\section{References}

Adelman, C. (1996) Anything Goes. Evaluation, 2(3), 291-305.

Biesta, G. (2006) Coming into presence in Beyond learning: Education for a human future. Boulder, Co: Paradigm Publishers.

Davis, B and Phelps, R. (2005). Exploring the common spaces of education and complexity: transphenomenality, transdisciplinarity, and interdiscursivity. Complicity: An International Journal of Complexity and Education, 2(1), 1-4.

Edwards, R (1997) Boundaries, Field and Moorland. In Changing places? Flexibility, lifelong learning, and a learning society. London: Routledge.

Edwards (2006) Beyond the moorland? Contextualising lifelong learning, Studies in the Education of Adults, 38(1), 25-36.

Gough, N (1991) Curriculum journalism for a postmodern society. Notes for a presentation in a symposium, 'Liberating curriculum writing: critical perspectives on the roles and functions of curriculum journals in curriculum work', at Liberating the Curriculum (Australian Curriculum Studies Association Conference, Adelaide, 11-14 July 1991).

Osberg, D and Biesta, G (2007) Beyond presence: Epistemological and pedagogical implications of "strong" emergence. Interchange, 38(1), 31-51.

(C) Copyright 2008. The authors, DEBORAH OSBERG, WILLIAM E. DOLL (JR.) and DONNA TRUEIT, assign to the University of Alberta and other educational and non-profit institutions a non-exclusive license to use this document for personal use and in courses of instruction provided that the article is used in full and this copyright statement is reproduced. The authors also grant a non-exclusive license to the University of Alberta to publish this document in full on the World Wide Web, and for the document to be published on mirrors on the World Wide Web. Any other usage is prohibited without the express permission of the authors. 